
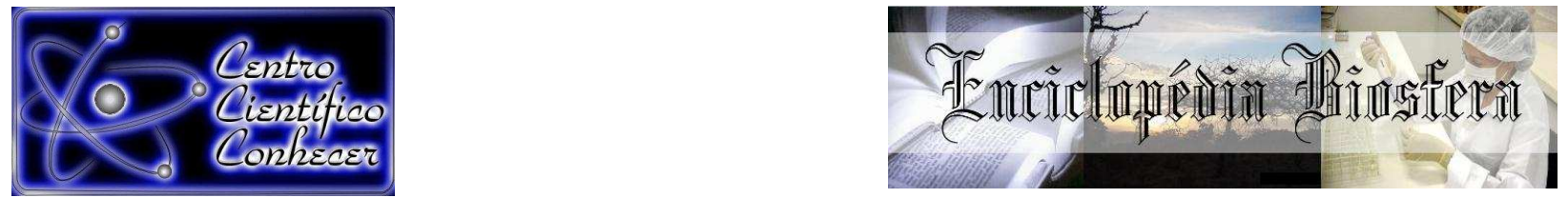

\title{
TUMOR VENÉREO TRANSMISSÍVEL EM GLOBO OCULAR DE CÃO - RELATO DE CASO
}

Alessandra Castro Rodrigues ${ }^{1}$, Érica Almeida Viscone ${ }^{1}$, Mariana Ribeiro de Castro ${ }^{1}$, Samyla de Almeida Silva1, Alessandra Aparecida Medeiros-Ronchi ${ }^{2}$

1- Residente em Patologia Animal, Universidade Federal de Uberlândia, Uberlândia MG. E-mail: alessandracastroveterinaria@gmail.com

2- Professor doutor em Patologia Animal, Universidade Federal de Uberlândia, Uberlândia - MG.

Recebido em: 03/10/2016 - Aprovado em: 21/11/2016 - Publicado em: 05/12/2016 DOI: 10.18677/EnciBio_2016B_099

\begin{abstract}
RESUMO
O tumor venéreo transmissível (TVT) é uma neoplasia maligna de células redondas, de origem supostamente histiocítica. É uma patologia bem conhecida e comumente diagnosticada em cães, principalmente naqueles que tenham acesso à rua e contato com animais errantes, isto porque é transmitido através do transplante de células tumorais viáveis seja pelo coito, forma mais comumente vista, ou pelo contato do tumor com mucosas e soluções de continuidade. Este trabalho teve como objetivo relatar caso de TVT de localização incomum em cão macho, adulto, sem raça definida, que foi encaminhado ao setor de Patologia Animal da Universidade Federal de Uberlândia para realização de necropsia. À necropsia observou-se massa no globo ocular medindo aproximadamente $1,5 \mathrm{~cm}$ de diâmetro, de consistência friável, coloração avermelhada intercalada com áreas esbranquiçadas e massa na base do pênis de aproximadamente $2,0 \mathrm{~cm}$ de diâmetro e com as mesmas características da massa no olho. Microscopicamente, observou-se células arredondadas, exibindo moderado pleomorfismo, basofílicas, citoplasma em quantidade moderada, basofílico e apresentando vacúolos, núcleo central, esférico e basofílico. Foi diagnosticado tumor venéreo transmissível a partir das características morfológicas das células obtidas por punção aspirativa por agulha fina das massas no pênis e globo ocular. Trata-se de localização pouco comum de TVT e o teste citopatológico foi suficiente e adequado para o diagnóstico desta patologia.
\end{abstract}

PALAVRAS- CHAVE: caninos, neoplasia, olho.

\section{TUMOR TRANSMISSIBLE VENEREAL GLOBE IN DOG EYE - CASE REPORT}

\section{ABSTRACT}

The transmissible venereal tumor (TVT) is a malignant neoplasm of round cells, supposedly histiocytic origin. It is commonly diagnosed in dogs, especially those who have access to the street and contact with stray animals, this because it is transmitted through the viable tumor cell transplantation is the coitus, most commonly seen form, or by tumor contact with mucous membranes and continuity solutions. This study aimed to report the case of TVT unusual location male dog, adult mongrel, which was referred to the Animal Pathology Department, Federal University of Uberlândia for necropsy. At necropsy observed up mass in the eye measuring about $1.5 \mathrm{~cm}$ in diameter, friable, reddish interspersed with whitish areas and mass at the base of the penis of approximately $2.0 \mathrm{~cm}$ in diameter and with the same mass characteristics in eye. Microscopically observed rounded cells, showing moderate 
pleomorphic, basophilic cytoplasm in moderate quantity, basophilic and presenting vacuoles, core, spherical and basophilic. It was diagnosed transmissible venereal tumor from the morphological characteristics of the cells obtained by fine-needle aspiration of the masses in the penis and eyeball. It is unusual location TVT and Pap test was sufficient and suitable for the diagnosis of this pathology.

KEYWORDS: canine, cancer, eye.

\section{INTRODUÇÃO}

O tumor venéreo transmissível é uma neoplasia maligna de células redondas, que acomete principalmente os cães, cuja origem é supostamente histiocítica (DINGLI \& NOWAK, 2006; PARANZINI et al., 2015). É o único exemplo de neoplasia contagiosa transmitida pelo coito, mais especificamente através do transplante de células tumorais viáveis durante o ato sexual, e por essa razão é comumente diagnosticada em cães que tenham acesso à rua, a grandes concentrações de animais e contato com animais errantes (OSTRANDER, 2006; BRUNA et al., 2014). O fato de este tumor ser transplantável foi estudado, mas não foi encontrado nenhum vírus associado à transmissão (WOODS, 2013).

Outra forma de transmissão é via contato direto do tumor com as mucosas ocular, oral, nasal e soluções de continuidade na pele e está associado aos hábitos dos cães de farejar e lamber o órgão genital de outros cães (OSTRANDER, 2006; LIMA et al., 2013; BRUNA et al., 2014). Esta neoplasia pode acometer cães de ambos os sexos e raças, sendo mais comumente encontrada nas fêmeas e animais sem raça definida (SILVA et al., 2007; HUPPES et al., 2014).

Macroscopicamente, no exame clínico, essa neoplasia tem características como: aspecto friável, coloração avermelhada, sangramento fácil, inflamação, ulceração, odor ruim e alteração da forma do órgão (STOCKMANN et al., 2011). O diagnóstico definitivo é realizado por meio de exames de histopatologia e citologia (FLORÉZ et al., 2012). O exame citológico é comumente utilizado, pois é de fácil acesso, rápido, de baixo custo, com poucos danos ao animal e ainda, possui grande eficácia para o diagnóstico de neoplasias de células redondas (BRACARENSE \& REIS, 1997).

Segundo SANTOS \& MARCOS (2011), o diagnóstico no tumor venéreo transmissível é simples e observa-se na citopatologia uma população de células redondas, com citoplasma que apresenta pequenos vacúolos vazios de limites bem definidos. As células têm núcleo redondo com até dois pequenos nucléolos evidentes. As mitoses podem ocorrer em grande quantidade, indicando que o tumor está crescendo exponencialmente.

Os tumores venéreos transmissíveis podem ser classificados em padrões morfológicos: plasmocitóide, linfocitóide e misto. Os plasmocitóides possuem mais de $60 \%$ das células com morfologia ovóide, citoplasma abundante e núcleo excêntrico; já os linfocitóides possuem mais de $60 \%$ de células com formato arredondado, núcleo redondo e central, citoplasma escasso e com vacúolos citoplasmáticos na periferia e os mistos possuem a mesma quantidade de células de ambos (FLORÉZ et al., 2012).

O objetivo deste trabalho foi relatar um caso de tumor venéreo transmissível em globo ocular de cão, visto que este tumor é encontrado raramente nesta localização.

\section{RELATO DE CASO}

Um cão, macho, adulto, sem raça definida, foi encaminhado ao Hospital Veterinário da Universidade Federal de Uberlândia e o tutor informou que outro ENCICLOPÉDIA BIOSFERA, Centro Científico Conhecer - Goiânia, v.13 n.24; p.1053 2016 
profissional havia diagnosticado erliquiose e TVT na base do pênis. Relatou ainda que o animal estava em tratamento para estas doenças, com doxiciclina há 15 dias e havia sido realizada uma dose de vincristina.

$\mathrm{Na}$ anamnese foi constatado que o animal apresentava paresia, prostração, atrofia muscular generalizada, desidratação moderada, mucosa oral normocorada, mucosa peniana hipercorada com massas de formato irregular na base do pênis, intensa secreção ocular bilateral e secreção nasal com ressecamento do focinho. $O$ globo ocular esquerdo apresentava-se com protusão, esclera avermelhada e córnea opaca com área deprimida central.

Foram realizados como exames complementares, hemograma e pesquisa de hemoparasitas, constatando-se trombocitopenia, linfopenia e resultado negativo para a investigação de parasitas no sangue. Não foi solicitado exame citológico da massa localizada no pênis. O diagnóstico clínico foi de erliquiose, cinomose e TVT genital. A lesão no globo ocular esquerdo foi diagnosticada clinicamente como úlcera de córnea.

$O$ animal foi internado, submetido a hidratação com ringer lactato e medicado com doxiciclina (10mg/kg IV BID), ranitidina (2mg/kg SC BID), ondansetrona $(0,5 \mathrm{mg} / \mathrm{kg}$ IV BID) e diazepan $(0,5 \mathrm{mg} / \mathrm{kg}$ IV BID). O mesmo não resistiu e foi a óbito cerca de 12 horas após o início do tratamento. O tutor solicitou avaliação necroscópica e o cão foi encaminhado ao laboratório de Patologia Animal.

\section{RESULTADOS E DISCUSSÃO}

$\mathrm{Na}$ necropsia, observou-se presença de uma massa localizada no globo ocular esquerdo, medindo aproximadamente $1,5 \mathrm{~cm}$ de diâmetro, consistência friável, superfície irregular, coloração avermelhada intercalada com áreas esbranquiçadas (Figura 1). Havia outra massa localizada na base do pênis, medindo aproximadamente $2,0 \mathrm{~cm}$ de diâmetro com as mesmas características macroscópicas da massa anterior.(Figura 2). Foi realizado o exame de punção aspirativa por agulha fina (PAAF) nas massas e o material obtido utilizado para confecção de esfregaços citológicos. Posteriormente as lâminas foram submetidas à coloração com Panótico Rápido ${ }^{\circledR}$ e examinadas em microscopia de luz, objetiva 100x (MARCOS \& SANTOS, 2011).

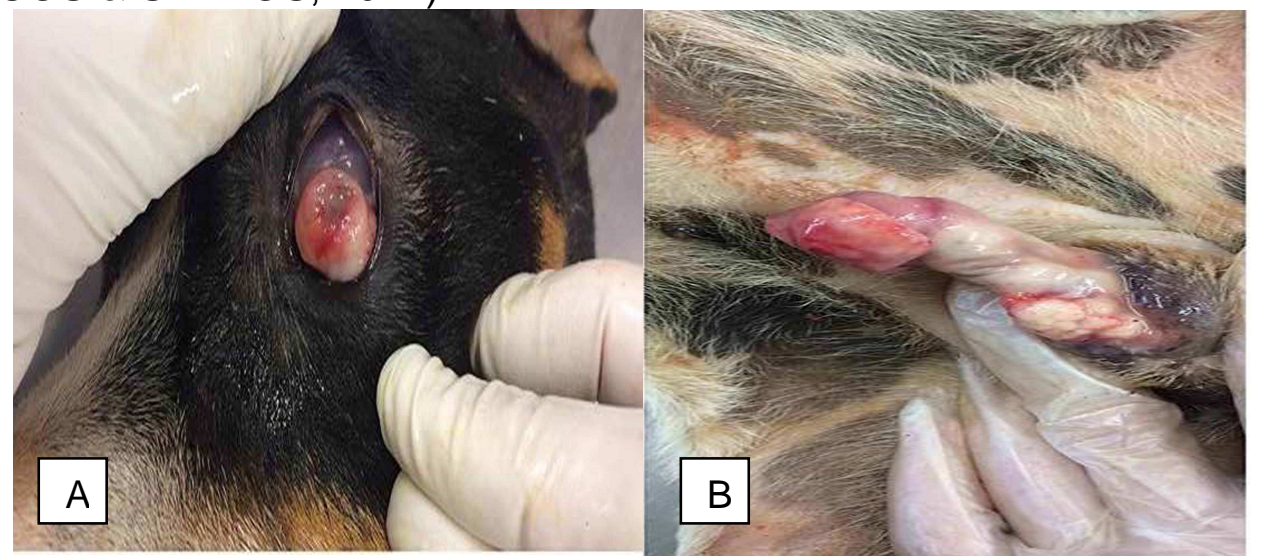

FIGURA 1 - Cão, sem raça definida, adulto. (A) Massa friável, avermelhada, localizada no globo ocular. (B) Massa localizada na base do pênis com características semelhantes à massa no globo ocular. Fonte: Arquivo pessoal. 
As características morfológicas das células obtidas pela PAAF foram: células redondas, com núcleo redondo de localização central, basofílico, citoplasma pouco corado e com vacúolos, nucléolo por vezes evidente e moderado pleomorfismo celular. Baseado nas características microscópicas observadas no exame citológico foi atribuído o diagnóstico de TVT ocular. A ocorrência de tumor venéreo transmissível no globo ocular é infrequente, sendo que a neoplasia mais encontrada nesta localização nos cães é o melanoma (DUBIELZING, 2002).

As características observadas no exame citológico são semelhantes às descritas por SANTOS \& MARCOS (2011) que descrevem como características do TVT população de células redondas, com citoplasma que apresenta pequenos vacúolos vazios de limites bem definidos. As células têm núcleo redondo com até dois pequenos nucléolos evidentes, as mitoses podem ocorrer em grande quantidade (Figura 3).

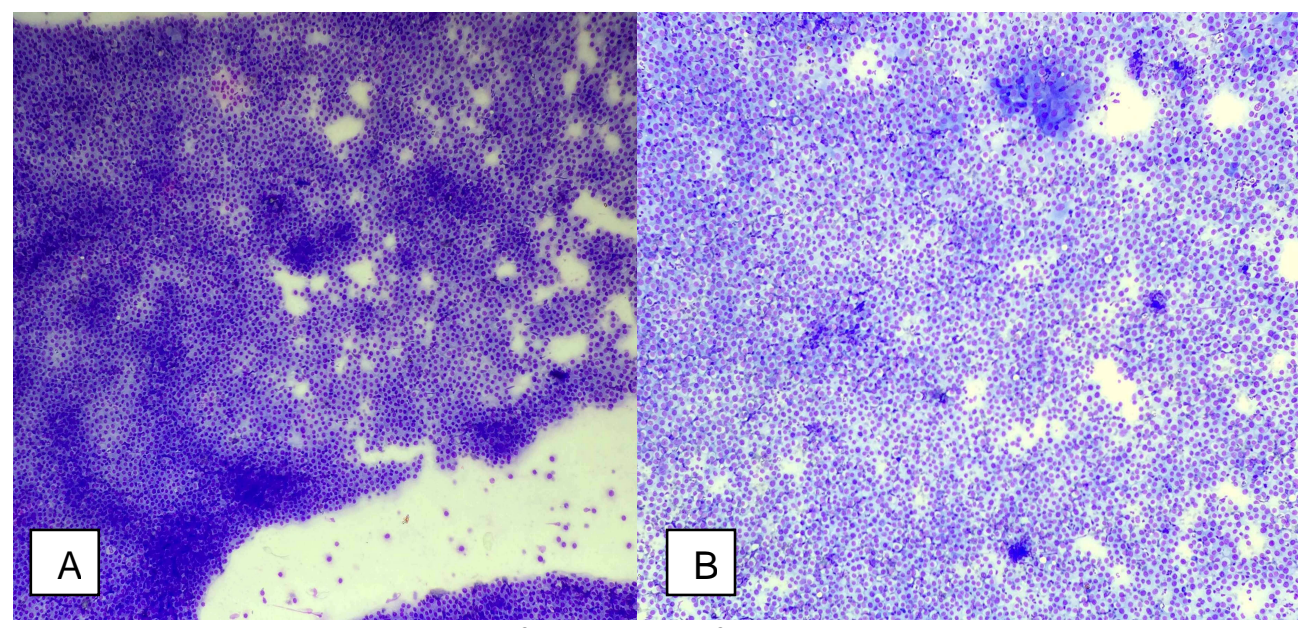

FIGURA 2. Fotomicrografia de esfregaço de PAAF de massa localizada no globo ocular (A) e na base do pênis (B) de cão, sem raça definida, adulto. Observar alta celularidade de células redondas. Objetiva 10x. Fonte: Arquivo pessoal.

O padrão morfológico das células tumorais do TVT descrito no presente trabalho foi o linfocitóide para as duas localizações (Figura 5). AMARAL et al. (2007) relataram que na localização genital o padrão morfológico mais comum é o linfocitóide, assim como observado no presente estudo. Porém, estes mesmos autores observaram que nas localizações extragenitais o padrão morfológico mais encontrado é o plasmocítico e que as metástases ocorrem com maior frequência em tumores com o padrão plasmocítico. No entanto, este relato ressalta que o padrão linfocitóide também pode metastatizar. 


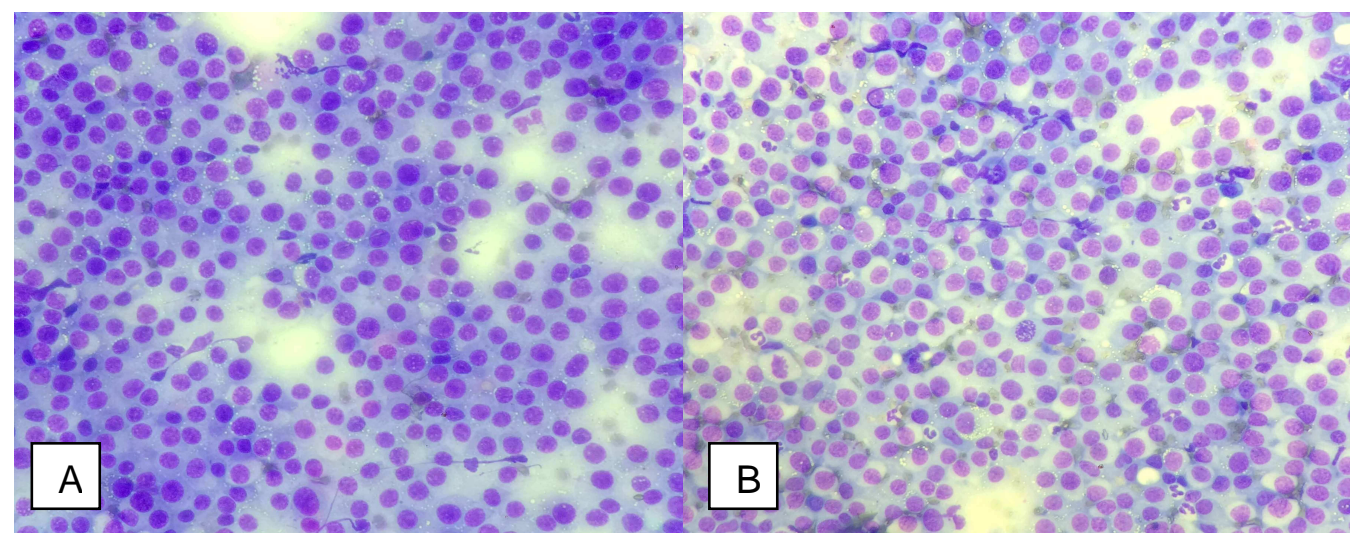

FIGURA 5 - Fotomicrografia de esfregaço de PAAF de massa localizada no globo ocular (A) e na base do pênis (B) de cão, sem raça definida, adulto. Observar alta celularidade, células redondas, com núcleos redondos, citoplasma escasso e com vacúolos. Objetiva 40x. Fonte: Arquivo pessoal.

O exame citológico para os casos de tumor venéreo transmissível é bastante conclusivo e muito utilizado na prática do diagnóstico desta neoplasia, com porcentagens altas de concordância com o exame histopatológico (BRACARENSE \& DOS REIS, 1997). Apesar do exame citológico ser útil no diagnóstico do TVT, o mesmo não foi solicitado no presente caso. Caso o mesmo fosse realizado na lesão do globo ocular, o diagnóstico equivocado de úlcera de córnea seria evitado. Além disso, o exame citológico permite que se tenha uma melhor visualização dos padrões morfológicos e critérios de malignidade quando comparado com o exame histológico (LIMA et al., 2013).

O TVT em localizações incomuns foi descrito por diversos autores, porém no globo ocular há somente dois relatos. BATISTA et al. (2007) relataram TVT como lesão primária no prepúcio com acometimento intraocular e metástase no baço em cão macho, adulto e sem raça definida. Já RODRIGUES et al. (2001) relataram caso de TVT intraocular com metástases nos linfonodos inguinais, num cão Terrier Brasileiro, com seis anos de idade. Os autores observaram massa avermelhada na esclera, na região temporal superior, que preenchia a câmara anterior do globo ocular direito.

Outros autores descreveram outras localizações incomuns de TVT, como BRUNA et al. (2014) que relataram TVT em conjuntiva, mucosa gengival e pele de cão macho, filhote, sem raça definida. Já REZAEl et al. (2016), relataram a localização primária desta neoplasia em cavidade oral e nasal de um cão, fêmea, adulto, sem raça definida. FERNANDES et al. (2013) e PINCZOWSKI et al. (2015), relataram casos de TVT na vulva com metástase para encéfalo, localização esta muito incomum para esse tipo de neoplasia. SANTOS et al. (2014), relataram metástase do TVT para glândula mamária de duas cadelas, adultas, sem raça definida. Foi realizado nos dois casos o tratamento com sulfato de vincristina com sucesso.

O tratamento de escolha para o TVT é a quimioterapia antineoplásica com a utilização de vincristina $\left(0,75 \mathrm{mg} / \mathrm{m}^{2}\right)$ por via intravenosa (IV), com intervalo entre as administrações de sete dias, totalizando de quatro até oito sessões. Caso o animal apresente resistência a este medicamento têm-se utilizado antineoplásicos alternativos como a doxorrubicina $\left(30 \mathrm{mg} / \mathrm{m}^{2}\right)$, IV, a cada 21 dias. Ambos, na maioria das vezes, resultam na remissão completa da neoplasia (HUPPES et al., 2014). 
Os efeitos colaterais deste tipo de tratamento como distúrbios gastrointestinais, anorexia, alopecia e hiperpigmentação da pele levam os tutores a desistirem do tratamento de forma errônea, pois estes sintomas podem ser controlados. Além disso, muitos tutores não completam o tratamento até a total remissão do tumor devido a necessidade de levar o paciente por várias vezes ao médico veterinário, as despesas com exames para o acompanhamento do tratamento e o valor dos quimioterápicos antineoplásicos (HUPPES et al., 2014).

O tratamento cirúrgico não é considerado efetivo, visto que a maioria dos tumores ocorrem nos órgãos genitais que são locais de difícil acesso, ocasionando na retirada da neoplasia sem margem de segurança e aumentando assim o número de recidivas (SILVA et al., 2007).

No caso de localizações infrequentes de TVT, vários autores relatam sucesso na utilização da quimioterapia com vincristina (BRUNA et al., 2014; SANTOS et al., 2014). Já REZAEI et al. (2016) relataram tratamento com vincristina em TVT localizado na cavidade oral e nasal, porém o cão veio a óbito no decorrer do tratamento. No presente relato o animal havia recebido uma dose, que não promoveu remissão da massa tumoral e também morreu antes do final do tratamento.

A prevenção deve ser feita a partir de campanhas que esclareçam aos tutores sobre a importância da restrição ao contato do cão com outros cães de rua, pois este pode encontrar animais que represente reservatórios em potencial para o TVT e contrair a doença (SILVA et al., 2007), visto que esta patologia se restringe ao cão doméstico (Canis familiaris) e potencialmente em outros canídeos sociais, como o lobo cinzento (Canis lupus) e o coiote (Canis latrans)( STOCKMANN et al., 2011).

Este trabalho, em conjunto com os relatos de BATISTA et al. (2007) e RODRIGUES et al. (2001) que relataram TVT em globo ocular, alerta sobre a importância do tumor venéreo transmissível como diagnóstico diferencial em neoplasias nesta localização. O diagnóstico de TVT no olho pode evitar que o animal seja submetido a procedimentos cirúrgicos invasivos sem que seja necessário, uma vez que o TVT regride com quimioterapia com sulfato de vincristina (LIMA et al., 2013).

\section{CONCLUSÃO}

O tumor venéreo transmissível é uma neoplasia que se localiza com mais frequência nos órgãos genitais de cães, mas podem ser encontrados esporadicamente em outros locais, devendo assim ser incorporado mais comumente nos diagnósticos diferenciais clínicos de tumores extragenitais.

\section{REFERÊNCIAS}

AMARAL, A. S., BASSANI-SILVA, S., FERREIRA, I., DA FONSECA, L. S., DE ANDRADE, F. H. E., GASPAR, L. F. J., \& ROCHA, N. S. Cytomorphological characterization of transmissible canine venereal tumor Caracterização citomorfológica do tumor venéreo transmissível canino, 2007. Disponível em: https://www.researchgate.net/profile/Isabelle_Ferreira2/publication/235960971_Cyto morphological_characterization_of_transmissible_canine_venereal_tumor_Caracteriz acao_citomorfologica_do_tumor_venereo_transmissivel_canino_CIENCIAS_VETERI

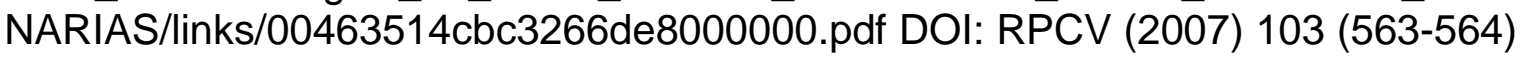

BATISTA, J. S., SOARES, H. S., PEREIRA, R. H. D. M. A., DE AQUINO PETRI, A., SOUSA, F. D. N., \& NUNES, F. D. C. R. Tumor venéreo transmissível canino com 
localização intra-ocular e metástase no baço. Acta Veterinaria Brasilica, v. 1, n. 1, p. 45-48, 2007. Disponível em: http://periodicos.ufersa.edu.br/revistas/index.php/acta/article/view/259 DOI: 10.21708/avb.2007.1.1.259.

BRACARENSE, A. P. F. R. L., \& DOS REIS, A. C. F. Citologia aspirativa em animais domésticos: estudo retrospectivo. Semina: Ciências Agrárias, v. 18, n. 1, p. 27-32, $1997 . \quad$ Disponível em: http://www.uel.br/revistas/uel/index.php/semagrarias/article/viewArticle/4254 DOI: 10.5433/1679-0359.1997v18n1p27

BRUNA, S., ANNALISA, N., ORLANDO, P., FEDERICA, M., FRANCESCO, L., \& BARBARA, L. Localizzazione congiuntivale di tumore venereo trasmissibile in un cane: segnalazione di un caso clinico. Veterinária, v. 28, n.2, p.23-26, 2014. Disponível em: http://hdl.handle.net/11588/597116 DOI:

DINGLI, D., \& NOWAK, M. A. Cancer biology: infectious tumour cells. Nature, v. 443, n. 7107, p. 35-36, $2006 . \quad$ Disponível em: http://www.nature.com/nature/journal/v443/n7107/full/443035a.html DOI: $10.1038 / 443035^{\text {a }}$

DUBIELZING R. R. Tumors of the eye. In Meuten D.J.,Tumors in domestic animals. $4^{\underline{a}}$ ed. lowa: lowa State Press; 2002.

FERNANDES, C. P. M., GASPAR, L. F. J., MEINERZ, A. R. M., GRECCO, F. B., NOBRE, M. O., \& CLEFF, M. B. Tumor venéreo transmissível canino com metástase encefálica. Semina: Ciências Agrárias, v. 34, n. 6Supl2, p. 3929-3934, 2013. Disponível

em: http://www.uel.br/revistas/uel/index.php/semagrarias/article/view/14863 DOI: 10.5433/1679-0359.2013v34n6Supl2p3929

FLORÉZ, M. M., PEDRAZA, F., GRANDI, F., ROCHA, N. S. Cytological subtypes of canine transmissible venereal tumor. Veterinary Clinical Pathology, v. 41, n. 1, p. 3-5, 2012. Disponível em: https://www.researchgate.net/profile/Fabrizio_Grandi/publication/221888098_Cytolog ic_subtypes_of_canine_transmissible_venereal_tumor/links/02e7e51e2cf9c1ed3600 0000.pdf DOI:10.1111/J.1939-165X.2012.00401.X

HUPPES, R. R., SILVA, C. G., USCATEGUI, R. A. R., DE NARDI, A. B., SOUZA, F. W., COSTA, M. T., ... \& FARIA, J. L. M. TUMOR VENÉREO TRANSMISSÍVEL (TVT): Estudo Retrospectivo De 144 Casos. Ars Veterinaria, v. 30, n. 1, p. 13-18, 2014. Disponível em: http://arsveterinaria.org.br/index.php/ars/article/view/785 DOI: http://dx.doi.org/10.15361/2175-0106.2014v30n1p13-18

LIMA, T. B., MARINHO, P. V. T., LIRA, R. N., JARK, P. C., MELO, J. F. P., \& OLIVEIRA, L. C. R. Apresentação atípica de tumor venéreo transmissível cutâneo em um cão. Veterinária e Zootecnia, v. 20, n. 1, p. 57-61, 2013. Disponível em: http://revistas.bvs-vet.org.br/rvz/article/view/17257/18116 
MARCOS R., SANTOS, M. Técnicas de colheita e coloração de esfregaços. In M. C. Peleteiro M. C., Marcos R., Santos M., Correia J., Pissara H., Carvalho T. Atlas de citologia veterinária, p. 1-27, 2011.

OSTRANDER, E. A. The singular history of a canine transmissible tumor. Cell, v.126, n.3, p.445-447, 2006. Disponível em: http://www.sciencedirect.com/science/article/pii/S0092867406009676 DOI: 10.1016/j.cell.2006.05.051

PARANZINI, C. S., SANT'ANNA, M. C., DI SANTIS, G. W., \& MARTINS, M. I. M. Prevalência dos diferentes tipos morfológicos de tumor venéreo transmissível e a associação com o prognóstico dos cães tratados com sulfato de vincristina-Estudo retrospectivo. Semina: Ciências Agrárias, v.36, n.6, p.3795-3800, 2015. Disponível em: http://www.uel.br/revistas/uel/index.php/semagrarias/article/view/19691 DOI: 10.5433/1679-0359.2015v36n6p3795

PINCZOWSKI, P., GIMENO, M., ACENA, C., VILLEGAS, A., DE MARTINO, A., \& LUJAN, L. Brain metastasis in a case of canine transmissible venereal tumor after a supposed successful treatment with vincristine sulfate. Acta Veterinaria-Beograd, v. 65, n. $1, \quad$ p. 137-142, 2015. Disponível em: https://www.degruyter.com/downloadpdf///acve.2015.65.issue-1/acve-20150011/acve-2015-0011.xml DOI: 10.1515

REZAEI, M., AZIZI, S., SHAHHEIDARIPOUR, S., \& ROSTAMI, S. Primary oral and nasal transmissible venereal tumor in a mix-breed dog. Asian Pacific Journal of Tropical Biomedicine, v. 6, n. 5, p. 443-445, 2016. Disponível em: http://www.sciencedirect.com/science/article/pii/S2221169115308947 DOI: 10.1016/j.apjtb.2016.03.006

RODRIGUES, G. N., ALESSI, A. C., \& LAUS, J. L. Intraocular transmissible venereal tumor in a dog. Ciência Rural, v. 31, n. 1, p. 141-143, 2001. Disponível em: http://www.scielo.br/scielo.php?pid=S0103-

$84782001000100023 \&$ script=sci_arttext\&tIng=pt DOI: 10.1590/S010384782001000100023

SANTOS HORTA, R., DA FONSECA, L. S., MIRANDA, D. F. H., QUESSADA, A. M., DE ROCHA NETO, H. J., \& DE SOUSA SILVA, S. M. M. Tumor venéreo transmissível (TVT) com metástase para a glândula mamária. Acta Scientiae Veterinariae, v. 42, n. 1, p. 46, 2014. Disponível em : https://www.researchgate.net/profile/Rodrigo_Horta/publication/264261468_Tumor_v enreo_transmissvel_(TVT)_com_metstase_para_a_glndula_mamria_Transmissible_ venereal_tumor_(TVT)_with_metastasis_to_the_mammary_gland/links/53d641850cf 220632f3d937f.pdf DOI: 10.13140/2.1.1274.6881

SANTOS, M., MARCOS R. Aparelho Reprodutor. In Peleteiro M. C., Marcos R., Santos M., Correia J., Pissara H., Carvalho T. Atlas de citologia veterinária, $p$. 195-214, 2011.

SILVA, M. C. V., BARBOSA, R. R., DOS SANTOS, R. C., CHAGAS, R. S. N., \& COSTA, W. P. Avaliação epidemiológica, diagnóstica e terapêutica do tumor venéreo transmissível (TVT) na população canina atendida no hospital veterinário da 
UFERSA. Acta Veterinaria Brasílica, v. 1, n. 1, 2007. Disponível em: http://periodicos.ufersa.edu.br/revistas/index.php/acta/article/view/260 DOI: 10.21708/avb.2007.1.1.260

STOCKMANN, D.; FERRARI, H. F.; ANDRADE, A. L.; LOPES, R. A.; CARDOSO, T. C.; LUVIZOTTO, M. C. R. Canine transmissible venereal tumors: aspects related to programmed cell death. Brazilian Journal of Veterinary Pathology, v. 4, n. 1, p. $65-75$, 2011. Disponível

em: http://citeseerx.ist.psu.edu/viewdoc/download?doi=10.1.1.475.2906\&rep=rep1\&type= pdf

WOODS J.P. Canine Transmissible Venereal Tumor. In: Withrow S.J., Vail D.M \& Page R.L.: Withrow \& MacEwen's Small Animal Clinical Oncology. 5th edn, p.692-696, 2013. 